\title{
A INOVAÇÃO NAS ORGANIZAÇÕES APOIADA PELA INTELIGÊNCIA COMPETITIVA EM AMBIENTES DE BIG DATA
}

Elvis Fusco, Marcos Luiz Mucheroni

Universidade de São Paulo - USP, Escola de Comunicações e Artes - ECA. São Paulo/SP. E_mail:fusco@univem.edu.br

\section{RESUMO}

Os ambientes informacionais digitais das organizações caracterizam-se pela dependência do uso da informação nos processos de tomada de decisão e inovação. Dentre os diversos esforços em utilizar as informações para apoiar as ações de apoio à decisão e a inovação nas organizações, está a Inteligência Competitiva, que utiliza-se de processos informacionais sistemáticos para sustentar tais ações. Neste contexto, este estudo pretende refletir sobre a inovação nas organizações por meio dos conceitos da Inteligência Competitiva em ambientes de Big Data utilizando uma plataforma informacional de apoio aos processos de inovação.

Palavras-chave: Inteligência Competitiva, Big Data, Inovação.

\section{INNOVATION IN ORGANIZATIONS SUPPORTED BY COMPETITIVE INTELLIGENCE IN ENVIRONMENTS OF BIG DATA}

\begin{abstract}
The contemporary setting of digital information environments of organizations characterized by dependence on the use of information in the processes of decision-making and innovation. Among the various efforts to use the information to support the actions of decision support and innovation in organizations, the Competitive Intelligence which uses the systematic information processes to support such actions. In this context, this study aims to reflect on innovation in organizations through the concepts of Competitive Intelligence in Big Data environments using an information platform to support innovation processes.
\end{abstract}

Keywords: Competitive Intelligence, Big Data, Innovation. 


\section{INTRODUÇÃO}

Atualmente vivencia-se uma nova disrupção tecnológica pela convergência da colaboração, mobilidade e grande volume de dados. O grande desafio para a pesquisa de ambientes computacionais e informacionais e para a forma de uso das informações nas organizações está em promover a integração destas tecnologias para balancear as necessidades de geração, acesso e controle destas informações, bem como as oportunidades deste comportamento emergente e suas inovações.

Este cenário em que as organizações estão inseridas exige uma evolução dos processos de gestão e de construção contínua de novos conhecimentos na geração da inovação tecnológica, ou seja, de seus produtos e serviços. Como resultado do uso da informação e da construção do conhecimento na promoção da inovação, há a geração de resultados a longo prazo, ou seja, considerando que as inovações são capazes de gerar vantagens competitivas, a médio e longo prazo, inovar torna-se essencial para que as organizações se mantenham estáveis e sustentáveis na sociedade contemporânea.

No cenário atual destas informações geradas nos ambientes organizacionais, principalmente nos que tem a Internet como plataforma, encontram-se dados que devido às suas características, atualmente classificam-se como Big Data. Fazer o melhor uso desses dados é essencial para uma organização que pretende inovar nos seus processos e se tornar cada vez mais competitiva ou estável. Neste contexto, este estudo pretende refletir sobre a inovação nas organizações por meio dos conceitos da Inteligência Competitiva em ambientes de Big Data utilizando uma plataforma informacional de apoio aos processos de inovação.

\section{INTELIGÊNCIA COMPETITIVA}

O cenário organizacional contemporâneo caracteriza-se pela dependência do uso da informação nos processos de tomada de decisão. Este contexto caracteriza-se também pela aceleração da inovação científica e tecnológica, rapidez na transmissão de informações em tempo real, gestão de informações não-lineares e ruptura com os conceitos de tempo e espaço.

Com as tecnologias de comunicação dos últimos anos, vivencia-se a Sociedade em Rede, com um conjunto de nós interconectados e flexíveis, potencializados pela Internet, que se transformou da Sociedade da Informação e que agora está toda conectada formando uma espécie de "teia" onde se entrelaçam pessoas, organizações e nações e por meio desses nós é que se produzem e disseminam todo e qualquer tipo de informação.

Em relação à gestão das organizações, o processo decisório é dependente do conhecimento do agente tomador de decisão e esse conhecimento é influenciado e determinado pelo seu acesso à informação de ambientes internos e externos às organizações, assim a informação é um recurso estratégico para obtenção de vantagens competitivas e fortalecimento da sustentabilidade das organizações.

Conforme identificado por Drucker (1995), a falta de acesso à informação gera a obsolescência do conhecimento nas organizações que faz com que haja uma queda na competitividade gerada pela incapacidade de inovar diante das informações intra e extra organizações.

Esse processo de acesso à informação tem sido revisto do ponto de vista dos Sistemas de Informação que historicamente se limitavam a levar em consideração as informações dos ambientes internos da organização e, neste contexto, a Inteligência Competitiva (IC) traz conceitos importantes para a ampliação do domínio de acesso à informação.

A Inteligência Competitiva é definida pela ABRAIC como um processo informacional pró-ativo que conduz à melhor tomada de decisão, seja ela estratégica ou operacional. É um processo sistemático que visa descobrir as forças que regem os negócios, reduzir o risco e conduzir o tomador de decisão a agir antecipadamente, bem como proteger o conhecimento gerado. Esse 
processo informacional é composto pelas etapas de coleta e busca ética de dados, informes e informações formais e informais tanto do macro-ambiente quanto do ambiente interno, análise de forma filtrada, integrada e respectiva disseminação (ABRAIC, 2015).

O processo de Inteligência Competitiva é realizado por meio da coleta ética e do uso da informação pública e disponível sobre tendências, eventos e atores no ambiente externo da organização, sistematizada para ser utilizada dentro da análise de cada organização.

A IC reforça a necessidade das organizações desenvolverem Competências Informacionais como Gestão da Informação e Conhecimento, Modelagem de Dados, Fluxos Informacionais, Gestão de Dados, Analytics, Processos Informacionais, entre outras.

O monitoramento do ambiente externo torna-se complexo se realizado de forma manual e por pessoas devido à amplitude e ao dinamismo informacional dos Ambientes Informacionais Digitais identificados como Big Data.

\section{A INFORMAÇÃO NA ERA DO BIG DATA}

Com o crescimento exponencial das informações contidas na Web e sua complexidade, ambientes informacionais digitais se deparam com um novo desafio: como conseguir tratar os processos informacionais de forma eficiente e desta maneira, por meio dessas informações, apoiar processos humanos e organizacionais num cenário em que a velocidade, o volume, a variedade das informações cresce a cada dia, e há ainda a necessidade de se levar em conta o valor e a veracidade da informação encontrada. Para entender este processo, é necessário entender a questão do Big Data, e como este processo está mudando a maneira como se lida com as informações no contexto da Web.

Vive-se um momento de grande geração e uso das informações geradas de forma online. Esses dados são gerados por e-mails, compartilhamento de informações por redes sociais, transações online, sensores, celulares, GPS, entre vários outros meios.

Zikopoulos, Eaton e Deroos (2012) definem de forma sintática que Big Data se aplica a informações que não podem ser processadas ou analisadas com as ferramentas e os métodos tradicionais. E diz ainda que a era do Big Data é resultado das mudanças que tem ocorrido no mundo, onde através dos avanços das tecnologias, foi possível que várias pessoas e programas se intercomunicassem não somente num intervalo de tempo, mas sim durante todo o tempo.

O termo Big Data não diz respeito somente ao aspecto de armazenamento de dado, mas também a outros aspectos como a velocidade em que os dados podem ser capturados e processados, quase que em tempo real, dando assim, vantagens competitivas as organizações (MCAFEE, 2012).

A seguir são indicados os três aspectos que McAfee (2012) considera principais neste processo que são o volume, a velocidade e a variedade: Volume - o número de dados gerados todos os dias na Web ultrapassam 2,5 exabytes, e este número tem dobrado a cada quarenta meses, em breve a unidade de medida de dados será o zetabytes. Todas as informações geradas são armazenadas, como dados financeiros, médicos, compras realizadas na internet, conversas realizados pelos mensageiros, gerando assim um volume extremamente grande de dados; Velocidade - muitas vezes a velocidade com que o dado é criado e processado é fundamental, pois estes dados podem ser utilizados em tempo real. Esta velocidade não está ligada somente a entrada de dados, mas também a velocidade do fluxo de dados. Ou seja, ter velocidade em conseguir acompanhar a geração e a demanda das requisições das informações; Variedade - as formas que os dados estão armazenados são cada vez mais diversas, entre elas textos, músicas, vídeos, imagens. E isto promove que não exista um padrão com que os dados são gerados e/ou armazenados.

Posteriormente a McAfee, alguns autores como Kakhani et. al. (2013) e Katal (2013), também incluíram outros dois conceitos que tem importância, para a definição de Big Data, que é 
a veracidade e o valor: Veracidade - todos os dados presentes neste universo podem ser das mais diversas naturezas, portanto é necessário que se tenha dados que sejam verdadeiros, para não trazer informações equivocadas, ao final de um estudo; Valor - a partir de dados e informações que foram fornecidas ou adquiridas pelos sistemas, pode se chegar a resultados de muito valor, pois podem demonstrar tendências do mercado, que pode levar aos administradores das empresas a tomarem medidas para mudar ou readequar as estratégias comerciais.

O processo do Big Data aparece pelo grande crescimento do uso e da geração da informação, onde a mudança quantitativa (grande crescimento de dados) trouxe uma mudança qualitativa das informações (informações cada vez mais precisas) (MAYER-SCHÖNBERGER E CUKIER, 2013). Compreender esse conceito e como as relações se estabelecem nesse cenário é essencial para promover a inovação nos processos organizacionais.

\section{INOVAÇÃO}

A inovação é prioridade em países desenvolvidos que têm como estratégia de crescimento e competitividade a diferenciação na pesquisa e desenvolvimento de novas tecnologias. A cultura de inovação de um país ou região depende da articulação dos principais atores da inovação, governo, empresas e instituições de ensino e pesquisa, que tem papeis distintos, porém colaborativos.

A inovação é conceituada por muitos autores, porém, por consenso, estabelece-se que esta somente se materializa quando pode ser explorada com sucesso. A inovação em suas diversas facetas e aplicações é fomentada em países desenvolvidos e países emergentes de forma contundente.

Segundo World Bank (2015), o Brasil investe discretamente em inovação. Em 2011, o país investiu 1,2\% do PIB em inovação, enquanto países como EUA e Coréia do Sul investiram 2,8\% e 4\%, respectivamente. Em valores nominais essa diferença pode ser notada com maior evidência. Enquanto o Brasil investiu em bilhões de dólares 19,4, os EUA e Coréia do Sul investiram 405,3 e 65,4 por ano, respectivamente.

A conclusão da pesquisa sobre inovação da Confederação Nacional da Indústria (CNI) no ano de 2015 no Brasil, mostra que 62\% dos empresários consideram baixo ou muito baixo o grau de investimento em inovação da própria indústria. De acordo com a CNI, o principal motivo para o Brasil estar atrasado em relação a outros países é o reflexo de defasagem tecnológica acumulada ao longo dos anos. A consequência disso é que a indústria, muitas vezes, acaba por importar ou copiar o que é feito em outros países. De acordo com os entrevistados, falta cultura de inovação nas empresas brasileiras em geral. Eles também elencaram como entraves a falta de políticas de incentivo, a dificuldade de interação entre empresas e universidades e o baixo nível de educação dos profissionais.

No entanto é importante destacar que justamente esta relação bem sucedida entre governo, iniciativa privada e universidades é a base da cultura de inovação de países desenvolvidos. Assim, estes são nomeados neste artigo como os atores de inovação. Desta forma, promover uma cultura inovadora é um legado que deve ser construído com esforço colaborativo entre os atores de inovação (governo, empresas e instituições de ensino e pesquisa).

\section{PLATAFORMA DE INTELIGÊNCIA COMPETITIVA COMO MODELO INFORMACIONAL DE APOIO À INOVAÇÃO}

Os fluxos informacionais caracterizam-se pelos processos de busca, acesso, recuperação, transformação, processamento, representação, persistência, transferência, apresentação e uso da informação. Neste contexto, com base nas fontes e produtos informacionais gerados e consumidos pelos principais atores da inovação, são utilizadas tecnologias computacionais, informacionais e ontológicas para apoiar o processo de gestão e a tomada de 
decisão no cenário da inovação. Assim, é proposta a criação de uma arquitetura de Inteligência Competitiva de apoio à inovação como pode ser visto na Figura 1.

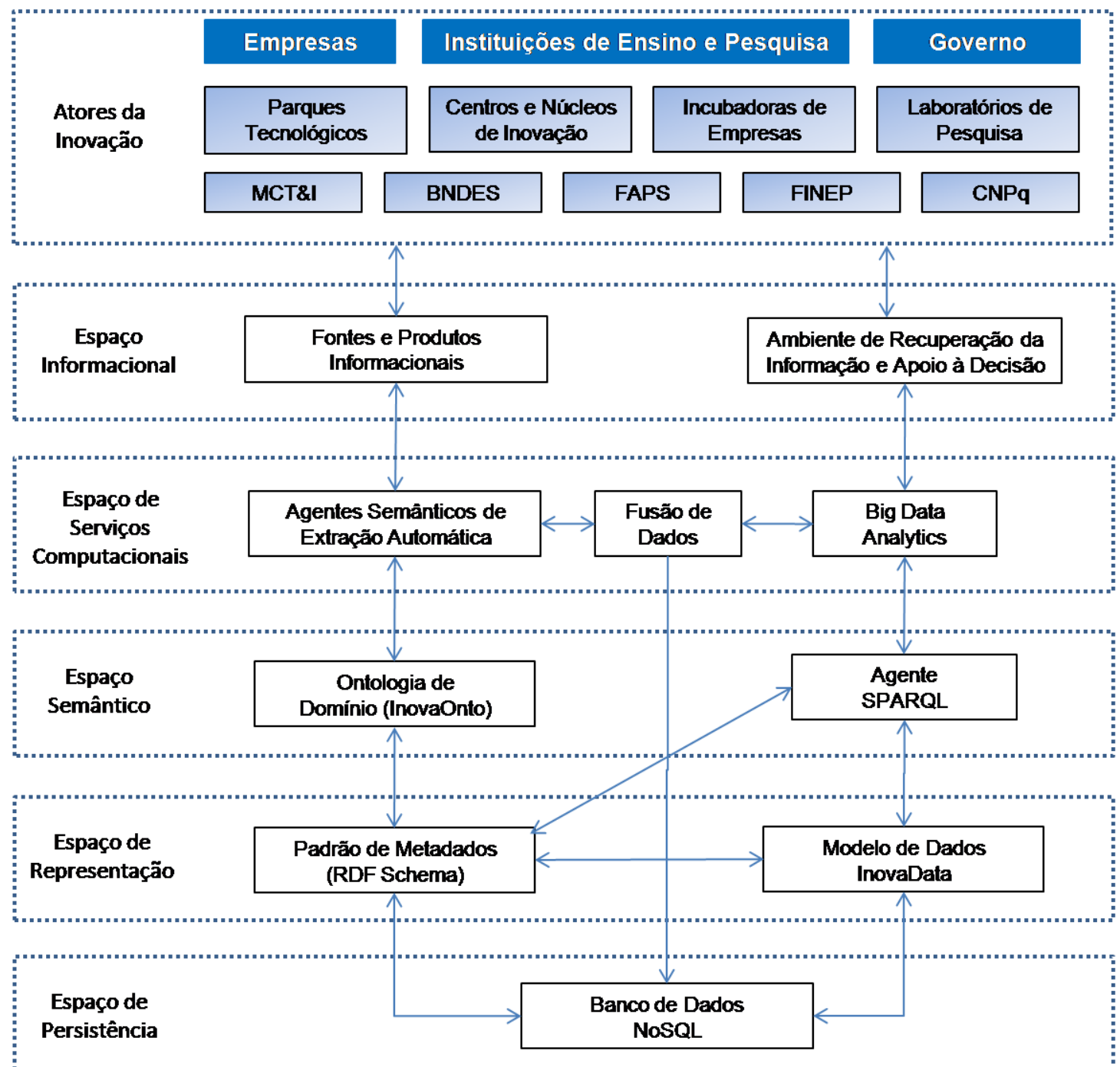

Figura 1. Arquitetura Proposta de Inteligência Competitiva de Apoio à Inovação (autoria própria)

A arquitetura proposta considera a premissa da colaboração dos principais atores nos processos da disponibilização da informação para suportar todo o fluxo informacional no qual esta plataforma se baseia.

\section{CONSIDERAÇÕES FINAIS}

O cenário atual em que as organizações estão inseridas exige uma evolução dos processos de gestão e de construção contínua de novos conhecimentos na geração da inovação tecnológica, ou seja, de seus produtos e serviços. Como resultado do uso da informação e da construção do conhecimento na promoção da inovação, há a geração de resultados a longo prazo, ou seja, considerando que as inovações são capazes de gerar vantagens competitivas, a médio e longo prazo, inovar torna-se essencial para que as organizações se mantenham estáveis e sustentáveis na sociedade contemporânea. Conceitos da Inteligência Competitiva figuram como possibilidade de se utilizar o grande volume de informação de ambientes internos e externos para apoiar as ações de apoio à decisão e a inovação nas organizações, a partir de processos informacionais sistemáticos para sustentar tais ações.

O Brasil atribuiu recentemente às suas estratégias de crescimento o investimento em inovação. A criação de leis de incentivos, programas governamentais de tecnologia e inovação, 
fundos de investimento, programas de formação de pesquisadores, internacionalização das universidades são algumas das ações realizadas, bem como a visão estratégica de que a inovação se dá pela articulação dos atores constituídos pelo governo, empresas e universidades, agregando valor e potencializando as ações e os investimentos realizados.

Este artigo apresentou uma reflexão sobre a inovação nas organizações por meio dos conceitos da Inteligência Competitiva em ambientes de Big Data, utilizando uma plataforma informacional de apoio aos processos de inovação. A utilização da combinação das tecnologias computacionais, informacionais e semânticas dos espaços contidos na plataforma que foram apresentados anteriormente, permite que os principais atores do domínio da inovação possam ter acesso aos produtos de informações gerados e colaborativamente apoiarem-se em processos de construção coletiva colaborativa de novos conhecimentos e em ações de incentivo à inovação nas organizações.

A gestão eficaz e a análise de dados em larga escala representam um interessante, mas crítico desafio, pois os modelos de gestão baseados na Inteligência Competitiva estão sendo influenciados por esse universo complexo de informações geradas com o conceito de Big Data e novas investigações são necessárias para dar solução a esse desafio de uso eficiente das informações no processo de gestão e de inovação.

\section{REFERÊNCIAS}

ABRAIC. Associação dos Analistas de Inteligência Competitiva. Disponível em <http://www.abraic.org.br>. Acesso em 25 de maio de 2015.

DRUCKER, P. Administrando em tempos de mudanças. São Paulo: Pioneira, 1995.

KAKHANI, M. K., KAKHANI, S., E BIRADAR, S. R. Research Issues in Big Data Analytics. S.L. S.D. 2013.

KATAL, A., WAZID, M., E GOUDAR, R. H. Big data: Issues, challenges, tools and Good practices. Contemporary Computing (IC3). 2013.

MAYER-SCHÖNBERGER, V., E CUKIER, K. Big data: A revolution that will transform how we live, work, and think. Houghton Mifflin Harcourt. 2013.

McAFEE, A., ET AL. Big Data. The management revolution. Harvard Bus Rev 90.10. 61-67, 2012.

WORLD BANK, Indicadores, Pesquisa e desenvolvimento (em\% do PIB), disponível em http://data.worldbank.org/indicator/GB.XPD.RSDV.GD.ZS, 2015. Acesso em 04 janeiro de 2016.

ZIKOPOULOS, P.; EATON, C.; DEROOS, D. Understanding bigdata: Analytics for enterprise class hadoop and streaming data. McGraw-Hill, New York, 2012. 